\title{
DESENVOLVIMENTO SOCIOECONÔMICO E EFICIÊNCIA TRIBUTÁRIA: UMA ANÁLISE DOS MUNICÍPIOS DE MINAS GERAIS
}

\section{SOCIOECONOMIC DEVELOPMENT AND TAX EFFICIENCY: AN ANALYSIS OF THE MUNICIPALITIES OF MINAS GERAIS \\ DESARROLLO SOCIOECONÓMICO Y EFICIENCIA FISCAL: UN ANÁLISIS DE LOS MUNICIPIOS DE MINAS GERAIS}

Recebido em: 21-08-2020

Avaliado em: 16-11-2020

Reformulado em: 03-12-2020

Aceito para publicação em: 22-03-2021

Publicado em: 15-04-202

Editor Responsável: Roberto Carlos Klann

\author{
Michelle Aparecida Vieira ${ }^{1}$ \\ Lucimar Antônio Cabral de Ávila ${ }^{2}$ \\ Jéssika do Vale Silva Lopes ${ }^{3}$
}

\section{RESUMO}

O estudo buscou investigar se e de que forma a eficiência tributária dos municípios mineiros varia em função do nível de desenvolvimento socioeconômico e da dependência do Fundo de Participação dos Municípios (FPM). Parte-se do pressuposto de que o desempenho tributário municipal pode ser afetado pela participação do FPM na receita total do município, o que implicaria na ineficiência tributária. Utilizando a Data Envelopment Analysis (DEA), observou-se que apenas 79 municípios foram eficientes e que 688 apresentaram $40 \%$ de ineficiência na exploração de sua base tributária. Dentre os municípios ineficientes, observou-se um potencial tributário não explorado, o que implica em perda tributária que acaba sendo compensada pelos recursos do FPM. Por outro lado, a eficiência tributária aumenta à medida que os níveis de desenvolvimento socioeconômico melhoram, o que corrobora as evidências empíricas no que diz respeito à necessidade de políticas públicas de desenvolvimento.

Palavras-Chave: Desenvolvimento socioeconômico. Eficiência tributária. FPM.

\footnotetext{
${ }^{1}$ Doutoranda em Ciências Contábeis; Universidade Federal de Uberlândia (UFU); E-mail: michellevieiracco@ gmail.com

${ }^{2}$ Doutor em Administração de Empresas; Professor do Departamento de Ciências Contábeis - Universidade Federal de Uberlândia (UFU); E-mail: lcavila@ufu.br

${ }^{3}$ Mestre em Administração; Universidade Federal de Viçosa (UFV); E-mail: jessikavs.adm@gmail.com
} 


\section{ABSTRACT}

The study sought to investigate how the tax efficiency of municipalities in Minas Gerais varies according to the level of socioeconomic development and the dependence on the Municipality Participation Fund (FPM). It is assumed that the municipal tax performance can be affected by the participation of the FPM in the total revenue of the municipality, which would imply tax inefficiency. Using the Data Envelopment Analysis (DEA), it was observed that only 79 municipalities were efficient and that 688 presented $40 \%$ inefficiency in exploiting their tax base. There was an untapped tax potential among the inefficient municipalities, which implies a tax loss that ends up being offset by FPM resources. On the other hand, tax efficiency increases as the levels of socioeconomic development improve, which corroborates the empirical evidence regarding the need for public development policies.

Keywords: Socioeconomic development. Tax efficiency. FPM.

\section{RESUMEN}

El estudio buscó investigar cómo varía la eficiencia tributaria de los municipios de Minas Gerais según el nivel de desarrollo socioeconómico y la dependencia del Fondo de Participación Municipal (FPM). Se asume que el desempeño tributario municipal puede verse afectado por la participación del FPM en la recaudación total del municipio, lo que implicaría ineficiencia tributaria. Utilizando el Análisis Envolvente de Datos (DEA), se observó que solo 79 municipios fueron eficientes y que 688 presentaron $40 \%$ de ineficiencia en la explotación de su base imponible. Entre los municipios ineficientes, existía un potencial tributario desaprovechado, lo que implica una pérdida tributaria que termina siendo compensada con los recursos del FPM. Por otro lado, la eficiencia tributaria aumenta a medida que mejoran los niveles de desarrollo socioeconómico, lo que corrobora la evidencia empírica sobre la necesidad de políticas públicas de desarrollo.

Palabras clave: El desarrollo socioeconómico. Eficiencia fiscal. FPM.

\section{INTRODUÇÃO}

A atuação do Estado na sociedade realiza-se a partir de sua função alocativa, pela qual bens e serviços são ofertados, por meio de recursos públicos provenientes da arrecadação tributária, em prol do desenvolvimento socioeconômico (Costa, Ferreira, Braga, \& Abrantes, 2015). No Brasil, a arrecadação de tributos é exercida pelos três níveis de governo (União, Estados e Municípios), resultado da descentralização fiscal impulsionada pela Constituição Federal de 1988 (CF/88), que priorizou os municípios com ampliação de suas competências tributárias.

Embora a reforma constitucional de 1988 tenha contribuído para o aumento da receita própria dos municípios, a participação municipal na arrecadação tributária nacional ainda é pequena, alcançando apenas 6,17\% em 2016 (FGV, 2020). Esse baixo desempenho deve-se basicamente à centralização das competências tributárias no Brasil, no sentido de que concentrando recursos na União, para depois redistribuí-los regionalmente, seria uma forma de atenuar as disparidades de capacidade de obtenção de recursos tributários entre as unidades federativas brasileiras (Cossio, 1998). Dessa forma, a necessidade de manter a eficiência do sistema tributário e de garantir a aplicação ótima de recursos, em determinados setores no nível subnacional de governo, fazem com que a arrecadação se mantenha centralizada (Baião, Cunha, \& Souza, 2017), tornando necessária a transferência de recursos da instância central aos governos subnacionais.

As transferências intergovernamentais constituem um importante instrumento de sustentação do federalismo fiscal e podem assumir duas principais formas: de propósito específico (ou condicionais), cujos recursos devem ser aplicados em áreas especificadas previamente; e de uso geral (ou incondicionais), que normalmente são obrigatórias e podem ser usadas da maneira que o receptor 
desejar (Oates, 1999). Conforme De Mello (2000), esses mecanismos de partilha de receitas são comuns nos países em desenvolvimento e atendem a objetivos múltiplos, como reduzir a lacuna fiscal, promover a equalização fiscal e o desenvolvimento regional, além de estimular a eficiência tributária dos governos estaduais e locais. No entanto, por utilizarem diferentes critérios de distribuição e apresentarem características específicas, as transferências têm provocado impacto no comportamento fiscal dos governos, gerando controvérsias, sobretudo no que se refere aos recursos incondicionais.

Embora preservem a autonomia local e aumentem a equidade entre as jurisdições (Shah, 2007), sendo prescritas pela literatura do federalismo fiscal para fins de redistribuição de renda e equalização (Oates, 1999), as transferências incondicionais podem impor desafios adicionais ao equilíbrio de um sistema federativo (De Mello, 2000). A falta de condicionalidade no compartilhamento de receita pode reduzir o incentivo para os governos subnacionais gerenciarem recursos compartilhados com eficiência, além de gerar barreiras entre os custos e benefícios da provisão de serviços do setor público (De Mello, 2000). Como resultado, se uma grande parte dos gastos subnacionais é financiada por recursos compartilhados, os governos subnacionais podem se sentir motivados a subutilizar suas próprias bases tributárias (Shah, 1991), evidenciando, assim, baixa eficiência arrecadatória.

Cossio (1998) foi um dos pioneiros a investigar os efeitos das transferências intergovernamentais no comportamento fiscal dos entes federativos brasileiros. Ao analisar o sistema tributário nacional e as disparidades regionais existentes no país, o autor identificou que a elevação de transferências intergovernamentais ou a redução do peso das receitas próprias provocam a redução do esforço fiscal das unidades receptoras dessas transferências. Isso acontece, segundo o autor, pois o interesse em melhorar a eficiência na arrecadação tributária varia em função da importância dos recursos tributários próprios na estrutura de financiamento do setor público, isto é, do grau de dependência financeira. A partir de então, muitos estudos têm adotado essa perspectiva, evidenciando um incentivo à ineficiência tributária associado à existência das transferências (Orair \& Alencar, 2010; Gasparini \& Miranda, 2011; Mattos, Rocha, \& Arvate, 2011; Sousa, Araújo, \& Tannuri-Pianto, 2012; Siqueira, Lima, \& Paes, 2016; Lopes \& Vieira, 2019).

Não obstante, tais estudos desconsideram o papel da gestão pública das unidades de governo na obtenção de receitas tributárias, concentrando-se apenas no baixo volume de recursos tributários arrecadados frente às transferências recebidas. Portanto, focam no que os municípios arrecadam (arrecadação efetiva) e não no que poderiam arrecadar (arrecadação potencial), o que abre uma lacuna de investigação perseguida pelo presente estudo. Posto isso, sendo as transferências um mecanismo de compensação das diferenças de capacidade tributária entre os entes federativos, espera-se, do ponto de vista teórico, que a eficiência tributária não varie em função do nível de recursos recebidos via transferências, uma vez que ela depende do desempenho da gestão municipal em executar plenamente a sua competência tributária.

Dentre as transferências incondicionais recebidas pelos municípios brasileiros, o Fundo de Participação dos Municípios (FPM) é a mais importante. Ainda que o FPM seja uma transferência motivada pela equidade na disponibilidade de recursos para os diferentes entes federativos, muitas críticas recaem sobre as externalidades negativas provocadas na eficiência tributária dos governos receptores. Sobretudo, em razão dos critérios utilizados para a distribuição de seus recursos, que não refletem a verdadeira capacidade fiscal diferencial dos municípios brasileiros (Shah, 1991). Ao transferir de forma automática recursos financeiros aos municípios, sem exigir nenhum tipo de contrapartida, o FPM pode reduzir a eficiência tributária, uma vez que a gestão municipal tende a se esquivar do ônus político da arrecadação própria. Como por exemplo, pode-se citar a não atualização da planta genérica de valores dos imóveis, base de cálculo do IPTU, o que provoca a subutilização de suas bases tributárias (Tristão, 2002; Lopes \& Vieira, 2019).

A perspectiva adotada neste estudo é a de que, embora alguns municípios necessitem dos recursos advindos do FPM, em razão das diferenças na distribuição de competências tributárias e da necessidade de compensar as disparidades regionais em termos de capacidade arrecadatória, este não 
é necessariamente um problema, desde que eles estejam usando de modo eficiente sua base tributária. Em outras palavras, importa saber se a dependência do FPM compromete a eficiência dos municípios em arrecadar todo o seu potencial ao exercerem a sua competência tributária.

Para Campelo (2003), a eficiência da arrecadação municipal também é traduzida na capacidade desses municípios em transformar os recursos disponíveis em desenvolvimento socioeconômico e qualidade de vida para a população. Ao mesmo tempo em que a arrecadação tributária é primordial ao desenvolvimento socioeconômico (Mendes, Ferreira, Abrantes, \& Faria, 2018), o contrário também é verdade, na medida que regiões mais desenvolvidas tendem a ter bases tributárias maiores e, portanto, tem maior capacidade de formação e obtenção de receitas tributárias próprias.

Considerando que a finalidade maior da Administração Pública é maximizar o bem-estar da sociedade, otimizando o uso dos recursos públicos por meio de uma gestão fiscal eficiente, e que o município é o agente protagonista desse processo (Louzano, Abrantes, Ferreira, \& Zuccolotto, 2019), questiona-se: a (in)eficiência tributária municipal varia em função do nível de desenvolvimento socioeconômico e da dependência do FPM? Parte-se do pressuposto de que embora o potencial de geração de receitas públicas seja determinado pelo estágio de desenvolvimento socioeconômico (Cossio, 1998), essa relação pode ser afetada pela participação do FPM na receita total do município, o que implicaria na ineficiência tributária. Assim sendo, é possível que um município com alto índice de desenvolvimento apresente baixo nível de eficiência tributária (ineficiente), em razão da dependência pelas transferências intergovernamentais.

Salienta-se que o estudo não pretende contestar a importância e necessidade das transferências intergovernamentais, em face das características da estrutura tributária brasileira e do seu papel na redução das desigualdades regionais, tampouco defender a ideia de que o FPM, em particular, foi concebido para substituir a arrecadação própria. Pelo contrário, busca-se verificar se, mesmo diante do recebimento de tais recursos, os governos receptores exerceram suas competências tributárias com eficiência, ou se houve uma acomodação (ineficiência tributária) e consequente substituição de suas bases tributárias, sendo esse um efeito colateral potencial do FPM.

Para verificar essa relação, tomou-se como objeto de análise os municípios de Minas Gerais, por apresentarem distintas estruturas socioeconômicas, que imprimem um quadro de disparidades intermunicipais (Costa et al., 2015), verificado nos distintos níveis de recursos tributários arrecadados. Soma-se a esse aspecto as desigualdades regionais na distribuição dos recursos do FPM. É possível identificar municípios com baixa capacidade de arrecadação de impostos e que recebem menos recursos do FPM, coexistindo com outros que possuem alta capacidade de arrecadação e recebem transferências de FPM acima da média nacional (Firjan, 2019). Em razão dessas características, Minas Gerais configura-se em um cenário ideal de análise do papel do FPM no comportamento fiscal municipal.

O desafio da eficiência se torna ainda mais complexo em razão da escassez de recursos públicos, da dificuldade de equilibrar receitas e despesas e da criação de condições institucionais e econômicas, para que investimentos em políticas de desenvolvimento socioeconômico tenham resultados eficientes, eficazes e efetivos (Louzano et al., 2019). Logo, o estudo abre um precedente para que indicadores de eficiência tributária sejam utilizados como elementos condicionantes de um sistema de equalização de recursos públicos, sendo esta a principal contribuição prática da pesquisa.

Igualmente, a pesquisa contribui com a literatura do federalismo fiscal, fornecendo insights capazes de incitar discussões em torno dos efeitos da descentralização fiscal, especificamente quanto à autonomia financeira em prol da eficiência do setor público. Para Cossio (1998), a autonomia financeira pode ser atingida com maior participação das receitas tributárias próprias na estrutura de financiamento das unidades inferiores de governo. Pouco se sabe sobre a materialização da autonomia financeira dos municípios. Ao que parece, a autonomia não está sendo exercida em sua plenitude e potencialidade, evidenciando um formalismo, isto é, divergências entre o que está estabelecido e assegurado na Constituição e o que efetivamente tem sido praticado. 


\section{REVISÃO DE LITERATURA}

\subsection{Descentralização fiscal e composição das Receitas Públicas Municipais}

A descentralização fiscal consiste na devolução de fontes de receita e funções de despesas para as instâncias subnacionais de governo, ou seja, caracteriza-se pela participação mais acentuada dos níveis mais baixos do governo no financiamento e gastos públicos (De Mello, 2000). No Brasil, esse movimento foi experimentado com maior intensidade no período pós Constituição Federal de 1988 (CF/1988), que imprimiu uma nova configuração para as relações intergovernamentais, impondo uma nova dinâmica à distribuição de recursos tributários e dos gastos entre as esferas do governo.

Ao impulsionar o processo de descentralização fiscal no contexto brasileiro, o sistema de repartição de competências tributárias, definido pela Constituição Federal de 1988, se estrutura em consonância com a Teoria do Federalismo Fiscal. Segundo Oates (1999), o federalismo fiscal é caracterizado pela combinação de competências centralizadas e descentralizadas, que possibilitam a atribuição de funções fiscais para diferentes níveis de governo e os instrumentos fiscais apropriados para o desempenho dessas funções. Sobre as competências centralizadas, a Teoria do Federalismo Fiscal sustenta que o governo central deve ser responsável pela função estabilizadora e distributiva, visto que os governos locais dispõem de meios limitados para o controle macroeconômico e redução das diferenças de renda entre as regiões (Musgrave \& Musgrave, 1980). Por outro lado, a função alocativa deve ser descentralizada, já que a proximidade dos governos locais com a população permite a identificação de suas preferências e necessidades de forma mais rápida e barata, proporcionando ganhos de eficiência, cabendo ao governo central atuar de maneira colaborativa (Oates, 1999).

Para cumprir seu papel no fornecimento de bens e serviços públicos, o governo deve dispor de recursos suficientes para financiá-los. A teoria prescreve que a definição dos instrumentos tributários e dos níveis responsáveis por sua gestão deve ser orientada pelo princípio do benefício, segundo o qual cada indivíduo contribui de acordo com os benefícios obtidos pelos serviços prestados pelos governos (Oates, 1999). Conforme o modelo de Tiebout (1956), os fatores de produção de maior mobilidade espacial devem ser tributados pelo governo central, ao passo que fatores com nenhuma mobilidade (imóveis) seriam tributados com maior eficiência pelo governo local. Dessa forma, no Brasil, cabe aos municípios a competência de cobrar impostos incidentes sobre a Propriedade Predial Territorial (IPTU), Serviços de Qualquer Natureza (ISS) e Transmissão Inter Vivos de Bens Imóveis (ITBI), além de taxas de uso geral e contribuições de melhoria, dentre os quais o IPTU e o ISS são os mais representativos.

As evidências empíricas têm demonstrado que a atribuição de competências tributárias aos municípios não foi o bastante para garantir a suficiência financeira das distintas unidades de governo, que têm apresentado baixa arrecadação própria (Souza, Silva, Ferreira, \& Abrantes, 2007; Veloso, 2008; Massardi \& Abrantes, 2015). Isso porque a participação das esferas inferiores de governo na arrecadação global não é determinada apenas pela atribuição legal de competências tributárias, das quais o município responde por uma menor parcela, mas, sobretudo, pela composição da carga tributária e pela distribuição regional de bases de tributação (Cossio, 1998).

Considerando que o Brasil é um país de grande extensão territorial, as diferenças regionais no grau de desenvolvimento econômico levam a existência de bases de tributação desigualmente distribuídas, impondo a necessidade da centralização de recursos tributários nas mãos da União e sua redistribuição, mediante transferências intergovernamentais, como forma de evitar uma provisão desigual de bens públicos. Esse compartilhamento de receitas visa minimizar esses desequilíbrios que surgem do processo de descentralização e que geram diferenças nas capacidades fiscais entre as jurisdições de mesmo nível de governo (Cossio, 1998).

A literatura aponta que o fraco desempenho da arrecadação municipal pode ser explicado por fatores de ordem econômica, técnica e política. Os fatores econômicos se referem à limitação da base 
tributária municipal, a qual, definida pelo grau de desenvolvimento econômico, determina a totalidade de recursos existentes na localidade e que poderiam ser apropriados, caso o município exercesse plenamente sua competência tributária (fossem eficientes) (Cossio, 1998). Os aspectos de ordem técnica se referem à ausência de instrumentos básicos de gestão tributária, tais como mapeamento de unidades territoriais, informatização, cadastro atualizado de imóveis (IPTU) e de contribuintes de ISS, além de um corpo burocrático eficiente na gestão tributária (Moraes, 2006; Orair \& Alencar, 2010). Por sua vez, o aspecto político se refere aos custos inerentes à arrecadação do IPTU, em razão da vulnerabilidade política das administrações municipais a pressões dos contribuintes, especialmente nas cidades de pequeno porte, cuja proximidade dos eleitores locais com seus governantes é maior (Moraes, 2006). Como os municípios tendem a evitar o ônus político da imposição tributária, buscam limitar-se aos recursos repassados pelas outras instâncias governamentais (Tristão, 2002).

principal transferência do governo federal para os municípios é Fundo de Participação dos Municípios (FPM), cuja criação remete à Constituição Federal de 1946, por meio da Emenda Constitucional $n^{\circ}$ 18/1965. Nessa ocasião, estabeleceu-se que $10 \%$ do produto da arrecadação do Imposto sobre a Renda e Proventos de Qualquer Natureza (IR) e do Imposto sobre Produtos Industrializados (IPI) seriam destinados à formação do fundo. Desde sua criação sofreu várias alterações em sua composição (alíquotas) e critérios de distribuição, sendo a mais expressiva feita pela $\mathrm{CF} / 88$, que aumentou gradativamente o seu percentual de participação no IR e no IPI para 22,5\% a partir de 1993. Atualmente, o FPM responde por $24,5 \%$ da arrecadação líquida do IR e do IPI e representa mais da metade das receitas disponíveis dos pequenos municípios brasileiros.

De acordo com Veloso (2008), o FPM é utilizado como um instrumento de política fiscal do governo federal, cujo principal objetivo é equilibrar os orçamentos dos municípios, proporcionando estabilidade, compensação e redistribuição de recursos. Seu caráter redistributivo se deve a constituição de seus recursos, que são provenientes de impostos cuja arrecadação se concentra nas localidades mais desenvolvidas e é distribuído basicamente por critério populacional, independente da base arrecadatória (Veloso, 2008). Desse modo, independente da sua atividade econômica, o município receberá a transferência do FPM.

O FPM concede ampla autonomia subnacional na alocação dos recursos, uma vez que se trata de uma transferência não vinculada e sem contrapartida, permitindo a maximização dos benefícios sociais oriundos de sua aplicação em áreas de maior necessidade (Mendes, Miranda, \& Cossio, 2008; Veloso, 2008). Ainda, conforme Mendes et al. (2008), o FPM tem como característica a incondicionalidade, que não impõe qualquer obrigação de aplicação dos recursos, pelo governo receptor, em despesas específicas. Em razão dessas características, o FPM tem sido constantemente questionado, sobretudo no que se refere ao desincentivo à arrecadação própria dos governos receptores. Dessa forma, importa mensurar a eficiência tributária municipal e sua relação com o FPM.

\subsection{Eficiência tributária e esforço fiscal: condicionantes e efeitos no contexto municipal}

No Brasil, a eficiência foi aspirada pela Constituição Federal de 1988, em seu Art. 37, quando instituída, por meio da Emenda Constitucional n ${ }^{\circ} 19$ de 1998, como um dos princípios que norteiam a Administração Pública direta e indireta (Brasil, 1988). Esse anseio foi reforçado com a intensificação da descentralização fiscal, sob o argumento de que transferir o poder decisório aos níveis inferiores de governo proporcionaria ganhos de eficiência (De Mello, 2000).

De acordo com Costa et al. (2015), uma gestão pública eficiente é aquela capaz de incrementar os níveis de desenvolvimento socioeconômico, isto é, capaz de otimizar os recursos disponíveis e prover melhorias no bem-estar social. Um conjunto de estudos tem constatado o impacto da formação de receitas locais no desenvolvimento socioeconômico (Leroy, Abrantes, Almeida, Ferreira, \& Vieira, 2017; Mendes et al., 2018). Contudo, do ponto de vista da eficiência tributária, cujo interesse é a maximização de receitas que se pode obter a partir da exploração do potencial arrecadatório do 
município, a ênfase é dada ao papel do nível de desenvolvimento local na obtenção de recursos tributários, visto que a capacidade fiscal dos municípios está diretamente relacionada às características econômicas que determinam a sua base de tributação (Cossio, 1998), sendo esta a orientação adotada neste estudo.

Ao considerar os municípios agentes promotores do desenvolvimento, compreender sua eficiência tributária é necessária, tendo em vista que o reduzido número de competências tributárias e as disparidades regionais de capacidade arrecadatória impõem desafios relacionados à obtenção de recursos financeiros para suprir as necessidades da sociedade por bens e serviços. Soma-se a isso o fato do orçamento dos municípios ser composto basicamente por receitas de transferências, especialmente do FPM, o que significa que tais recursos financiam a maior parcela de gastos relacionados a execução de suas funções mais básicas. Esse quadro retrata uma situação de vulnerabilidade orçamentária enfrentada por parte dos municípios. Ao ter a maior parcela de seus recursos definidos de forma exógena, os municípios podem enfrentar graves dificuldades financeiras diante de decisões tomadas pelo governo federal que impliquem na redução desses recursos transferidos (Brito \& Brito, 2020).

A literatura do federalismo fiscal aponta alguns problemas associados às transferências incondicionais de recursos, com destaque para a 'preguiça fiscal' ou comportamento free rider, que ocorre quando o aumento das transferências provoca uma redução no esforço fiscal dos governos que as recebem (Oates, 1999), em razão da alta dependência fiscal (De Mello, 2000). Esses desdobramentos das transferências nas finanças locais podem repercutir na situação macroeconômica do país, representando um dos 'perigos da descentralização' discutidos por Prud'homme (1995), que abrem espaço para questionamentos relacionados à reestruturação dos sistemas de subsídios intergovernamentais, pautados em medidas de desempenho fiscal dos governos receptores.

No Brasil, destaca-se um corpo teórico que analisou o desempenho dos municípios no cumprimento de suas competências tributárias, relatando um potencial de expansão da arrecadação própria e o papel desestimulante das transferências intergovernamentais, tanto para o contexto nacional de modo geral (Orair \& Alencar, 2010; Gasparini \& Miranda, 2011; Mattos et al., 2011; Sousa et al., 2012; Orair \& Albuquerque, 2016), quanto para uma análise regionalizada (Souza et al., 2007; Massardi \& Abrantes, 2015; Siqueira et al., 2016; Fernandes \& Sousa, 2018; Lopes \& Vieira, 2019; Sobrinho \& Alencar, 2019).

Em uma análise agregada por estado, Orair e Alencar (2010) evidenciaram que em 2007, 41\% dos municípios brasileiros apresentaram um esforço fiscal abaixo da média nacional. Detalhadamente, identificaram que os municípios do Amapá apresentaram maior capacidade de expansão de sua arrecadação própria, visto que apenas $47 \%$ de sua capacidade tributária foi efetivamente explorada (ineficiência tributária), o que mostra que estes entes podem diminuir sua dependência em relação ao governo central. Por outro lado, os municípios de Alagoas possuíam menor espaço de expansão da arrecadação, pois foram os mais eficientes na exploração tributária, com um aproveitamento de $91 \%$ de toda a sua capacidade fiscal. Quanto ao efeito das transferências, observou-se uma relação negativa com a arrecadação própria.

Mattos et al. (2011) investigaram o efeito das transferências intergovernamentais em comparação com a renda do consumidor (efeito flypaper) na eficiência da arrecadação de impostos de 3.335 municípios brasileiros em 2004. O efeito flypaper se refere ao fenômeno no qual os gastos dos governos locais são mais sensíveis a aumentos nas transferências intergovernamentais do que a aumentos nas rendas privadas locais. Ao estabelecer a relação entre receita privada, transferências e os escores de eficiência, os autores observaram que as transferências incondicionais provocaram menor eficiência na arrecadação local.

Considerando apenas a transferência do FPM, Gasparini e Miranda (2011) avaliaram o a equidade dos serviços públicos, a eficiência alocativa de recursos (gastos) e a eficiência tributária dos municípios brasileiros. Sobre a eficiência na arrecadação de tributos, os autores constataram que o potencial tributário era melhor explorado em municípios maiores, principalmente para as regiões 
Sudeste e Sul do país. Além disso, verificaram também um potencial tributário não explorado, em razão de transferências intergovernamentais não necessárias. Quanto à avaliação do repasse ótimo de recursos redistributivos, observaram que caso fossem eficientes, muitos dos municípios analisados não seriam dependentes do FPM, em razão do potencial de expansão da arrecadação própria.

Do mesmo modo, Sousa et al. (2012) observaram baixa eficiência na arrecadação do IPTU, ISS e taxas de uso geral, sobretudo para os municípios pertencentes às regiões Norte e Nordeste, que por serem mais pobres, eram basicamente financiados por doações de esferas governamentais superiores. Os resultados da pesquisa de Orair e Albuquerque (2016) reforçam esses achados e avançam, ao demonstrar que além das transferências redistributivas (FPM), os repasses devolutivos, vinculados e compensatórios também afetavam o desempenho da arrecadação do IPTU dos municípios analisados.

Em uma análise regionalizada, o desestímulo arrecadatório provocado pelas transferências também foi verificado para municípios de Pernambuco (Siqueira et al., 2016), da Paraíba (Fernandes \& Sousa, 2018), da Bahia (Lopes \& Vieira, 2019), do Ceará (Sobrinho \& Alencar, 2019) e de Minas Gerais (Souza et al., 2007; Massardi \& Abrantes, 2015), especialmente no que se refere ao FPM, fortalecendo a necessidade de utilizar indicadores de eficiência tributária como um elemento condicionante do sistema de equalização de receitas. Por esse motivo, há um interesse crescente na necessidade de aumentar a capacidade tributária dos municípios e a eficiência da arrecadação de impostos, como forma de ampliar a participação das receitas tributárias próprias no financiamento das despesas locais (Sousa et al., 2012).

A receita tributária própria, ou arrecadação tributária, se refere ao montante efetivamente arrecadado pelos entes federativos, mediante exercício de sua autonomia financeira. Cossio (1998) define a receita tributária efetiva, ou observada, como resultado do emprego de um esforço de arrecadação por parte do governo local sobre a sua receita tributária potencial, que é a arrecadação que poderia ser alcançada se as bases tributárias fossem exploradas eficientemente (dada as características locais). Ou seja, utiliza-se um processo de estimação da receita tributária potencial como medida de capacidade fiscal (Cossio, 1998).

O esforço tributário, ou esforço fiscal, por sua vez, corresponde a razão entre a arrecadação efetiva e a aproximação da receita potencial, indicando a maneira como o município explora a sua capacidade tributária (Orair \& Alencar, 2010). Segundo Moraes (2006), o esforço fiscal é a medida que representa o esforço de arrecadar toda a receita tributária disponível em uma base tributária. Enquanto as características econômicas definem a capacidade de obtenção de recursos tributários de cada ente federativo, "o esforço de arrecadação mensura a eficiência da obtenção de receitas tributárias pelas administrações responsáveis" (Cossio, 1998, p. 55). Depende, portanto, da própria gestão tributária das unidades de governo em maximizar o nível de receitas que se pode obter, sem reduzir ou aumentar as variáveis que caracterizam a base de tributos local. Assim sendo, a (in) eficiência tributária dos municípios está condicionada às características de sua base tributária, que delimitam o estágio de desenvolvimento local e às externalidades provocadas pelas receitas oriundas das transferências intergovernamentais.

Face às discussões apresentadas, o estudo é orientado pela seguinte hipótese: Hipótese geral: a (in)eficiência tributária dos municípios mineiros está condicionada ao nível de desenvolvimento socioeconômico e ao grau de dependência do FPM.

A condição estabelecida pela hipótese geral do estudo partiu do pressuposto de que a base tributária local e, consequentemente, o nível de eficiência tributária de um município, é determinado pelo seu estágio de desenvolvimento socioeconômico, traduzido em melhores condições de renda, nível de atividade econômica, concentração populacional e grau de urbanização (Cossio, 1998; Veloso, 2008). Para Costa et al. (2015), um maior desenvolvimento amplia a capacidade de gerar receita própria para manter a gestão equilibrada. Dessa forma, parece existir uma relação positiva entre eficiência tributária e o desenvolvimento socioeconômico $\left(\mathbf{H}_{\mathbf{a}}\right)$. 
A dependência por transferências intergovernamentais também afeta diretamente a eficiência tributária dos entes receptores. Conforme Gasparini e Miranda (2011), obter recursos próprios exige mais esforço e desgaste político do que simplesmente receber transferências arrecadadas em outras localidades. Dessa forma, a eficiência tributária dos municípios se associa negativamente com o nível de dependência de transferências intergovernamentais, neste estudo, o Fundo de Participação dos Municípios $\left(\mathbf{H}_{\mathbf{b}}\right)$.

\section{PROCEDIMENTOS METODOLÓGICOS}

\subsection{Descrição da amostra}

Compreende a amostra deste estudo os municípios do estado de Minas Gerais. A escolha pelo estado mineiro se deu em razão de suas características econômicas, com o terceiro maior Produto Interno Bruto (PIB) do país. Além disso, o estado possui o maior número de municípios, 853 no total, dos quais aproximadamente $57 \%$ possuem população de até 10 mil habitantes, o que os coloca na mesma faixa de população para cálculo de distribuição do FPM-Interior, gerando elevada renda per capita do FPM para municípios pouco populosos (Mendes et al., 2008).

Tabela 1

Classificação dos municípios pertencentes à amostra

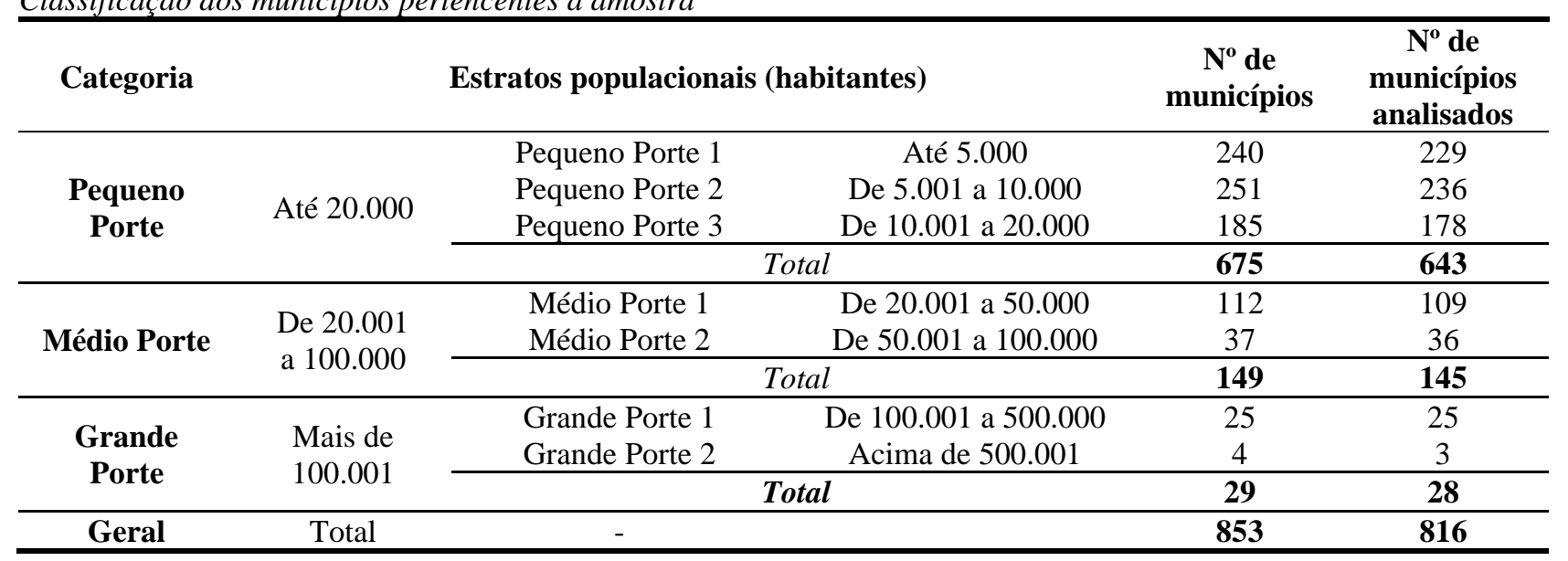

Fonte: Elaboração própria, com base nos critérios adotados por Veloso (2008).

Os municípios foram separados em 7 estratos populacionais e classificados em três categorias (pequeno, médio e grande porte), conforme critério definido pelo Instituto Brasileiro de Geografia e Estatística (IBGE) e adaptado por Veloso (2008). Quanto ao período, adotou-se o ano de 2016, por ser o último com o maior número de informações para um maior número de municípios. Em razão da indisponibilidade de dados para alguns municípios no período delimitado e da existência de outliers extremos, a amostra final do estudo é formada por 816 municípios, aproximadamente 95,6\% do total.

Essa análise estratificada é necessária devido a existência de relevantes diferenças nas características socioeconômicas locais, bem como às possíveis diferenças no comportamento da eficiência tributária desses entes em relação ao recebimento das transferências intergovernamentais (Veloso, 2008) e ao nível de desenvolvimento local (Costa et al., 2015).

\subsection{Estimação do Índice de Eficiência Tributária (IET)}

Para mensurar a eficiência tributária dos municípios mineiros, fez-se uso da modelagem Data Envelopment Analysis (DEA). A DEA é uma abordagem não paramétrica, baseada em programação matemática, especificamente na programação linear, para analisar as eficiências relativas das 
unidades tomadores de decisão (DMU's), neste caso, os municípios do estado de Minas Gerais (Tabela 1).

A DEA tem como objetivo determinar a eficiência de um conjunto de DMU's, considerando a existência de múltiplos inputs (entradas) e outputs (saídas) (Charnes, Cooper, \& Rhodes, 1978). No estudo, o intuito é estimar a receita potencial, ou capacidade fiscal do município, dada as características de sua base tributária. O índice de eficiência obtido seria, portanto, o resultado da otimização entre a arrecadação tributária efetiva dos municípios (produtos/ outputs), por um lado, e um conjunto de variáveis econômicas, que representariam a base tributária municipal (recursos/inputs).

A eficiência obtida a partir da DEA também pode ser entendida como esforço fiscal/tributário, visto que representa o empenho do município em obter o máximo de recursos tributários possíveis, dada a sua capacidade fiscal. Nesse sentido, as variáveis utilizadas para representar a capacidade fiscal e a base tributária dos municípios (inputs) e as receitas tributárias arrecadadas (outputs) estão descritas na Tabela 2:

Tabela 2

Descrição das variáveis utilizadas para mensuração da eficiência tributária- (capacidade tributária)

\begin{tabular}{|l|c|l|c|}
\hline \multicolumn{1}{|c|}{ Variável } & \multicolumn{1}{|c|}{ Sigla } & \multicolumn{1}{|c|}{ Base Teórica } & Fonte \\
\cline { 1 - 4 } $\begin{array}{l}\text { Valor Adicionado da Agropecuária per } \\
\text { capita }\end{array}$ & VA_agro_pc & Massardi e Abrantes (2015) & $\begin{array}{c}\text { IMRS } \\
\text { (FJP) }\end{array}$ \\
\hline $\begin{array}{l}\text { Valor Adicionado da Indústria per } \\
\text { capita }\end{array}$ & VA_ind_pc & Massardi e Abrantes (2015) & $\begin{array}{c}\text { IMRS } \\
\text { (FJP) }\end{array}$ \\
\hline $\begin{array}{l}\text { Valor Adicionado dos Serviços per } \\
\text { capita }\end{array}$ & VA_serv_pc & Massardi e Abrantes (2015) & $\begin{array}{c}\text { IMRS } \\
\text { (FJP) }\end{array}$ \\
\hline Produto Interno Bruto per capita & PIB_pc & $\begin{array}{l}\text { Veloso (2008); Cosio (1998); Massardi e } \\
\text { Abrantes (2015) }\end{array}$ & IBGE2 \\
\hline Taxa de urbanização & Tx_urb_pc & Sousa et al. (2012) & IBGE \\
\hline Outputs & Rec_trib_pc & $\begin{array}{l}\text { Massardi e Abrantes (2015); Sousa et al. } \\
\text { (2012) }\end{array}$ & $\begin{array}{c}\text { SICONFI } \\
\text { (STN) }\end{array}$ \\
\hline
\end{tabular}

Notas: ${ }^{1}$ Índice Mineiro de Responsabilidade Social/ Fundação João Pinheiro; ${ }^{2}$ Instituto Brasileiro de Geografia e Estatística; ${ }^{3}$ Sistema de Informações Contábeis e Fiscais do setor público brasileiro/ Secretaria do Tesouro Nacional. Fonte: elaboração própria.

A eficiência é um conceito relativo e que deve ser entendido como o que foi produzido, dado os recursos disponíveis, com o que poderia ter sido produzido com os mesmos recursos. Para que a eficiência relativa seja determinada, é necessário que as DMU's sejam comparáveis, isto é, sejam homogêneas entre si (Golany \& Roll, 1989). Objetivando homogeneizar a amostra, utilizou-se a técnica não hierárquica $K$-means da Cluster Analysis para criar três agrupamentos, compostos por municípios semelhantes entre si e diferentes entre os grupos. Por apresentarem comportamento homogêneo, apenas dentro dos grupos foi possível estimar os escores de eficiência e proceder a uma análise comparativa.

Levando em consideração que o interesse da análise recai sobre a eficiência tributária dos municípios, ou seja, o máximo de receitas que se pode obter sem reduzir ou aumentar as variáveis que caracterizam a base de tributos local, o modelo DEA adotado no estudo se baseia na "orientaçãoproduto", isto é, para a arrecadação tributária própria, e também assume rendimentos variáveis de escala, modelo BCC (Banker, Charnes, \& Cooper, 1984), assim como nos estudos de Gasparini e Miranda (2011) e Sousa et al. (2012). Dessa forma, são consideradas eficientes as DMU's que apresentam eficiência igual a 1 , ou seja, $100 \%$. 


\subsection{Análise das relações Eficiência Tributária, Desenvolvimento Socioeconômico e Dependência do FPM}

Conforme Diniz e Corrar (2011), na avaliação da eficiência é muito comum a incorporação de fatores exógenos que possam afetar os escores calculados. Neste estudo, depreende-se que o desempenho tributário dos entes municipais pode ser afetado por fatores não discricionários, como o estágio de desenvolvimento socioeconômico local $\left(\mathbf{H}_{\mathbf{a}}\right)$ e o grau de dependência financeira $\left(\mathbf{H}_{\mathbf{b}}\right)$.

Para verificar as hipóteses, foi utilizada a Regressão Quantílica (RQ), por ser mais robusta e permitir o relaxamento de pressupostos da regressão estimada por Mínimos Quadrados (MQO). A modelagem foi proposta por considerar que o nível de desenvolvimento socioeconômico e a dependência do FPM não influenciam, na mesma medida, o desempenho tributário dos municípios.

Assumindo que as variáveis explicativas não afetam igualmente o comportamento tributário dos municípios, foram estimadas regressões para os quantis 10\%, 25\%, 50\% (mediana), $75 \%$ e $90 \%$. O p-ésimo quantil condicional do IET é dado por:

$$
\begin{gathered}
Q_{\theta}(I E T \mid X)=\alpha+\beta_{\theta} X^{\prime}+\varepsilon \\
\theta \in[0,1]
\end{gathered}
$$

Em que: IET corresponde ao Índice de Eficiência Tributária dos municípios, representado pelo escore obtido pela aplicação da DEA; $\alpha$ representa o coeficiente angular da equação; $\beta_{\theta}$ é o parâmetro estimado para cada quantil condicional de variação na variável dependente; $X^{\prime}$ é o vetor de variáveis explicativas usadas no modelo e $\varepsilon$ é o termo de erro.

As variáveis independentes do modelo correspondem ao nível de desenvolvimento socioeconômico e a dependência do FPM e visam, respectivamente, testar as hipóteses de que a eficiência é afetada positivamente pelo nível de desenvolvimento socioeconômico dos municípios $\left(\mathbf{H}_{\mathbf{a}}\right)$ e negativamente pela dependência municipal em relação ao Fundo de Participação dos Municípios (FPM) $\left(\mathbf{H}_{\mathbf{b}}\right)$.

O desenvolvimento socioeconômico dos municípios foi representado pelo Índice Firjan de Desenvolvimento Municipal (IFDM), que abrange as áreas de saúde, emprego e renda e educação, cuja escala varia de 0 (mínimo) a 1 (máximo), para classificar o nível de cada localidade em quatro categorias: baixo (de 0 a 0,4$)$, regular $(0,4$ a 0,6$)$, moderado (de 0,6 a 0,8$)$ e alto $(0,8$ a 1) desenvolvimento. Sendo assim, quanto mais próximo de 1 , maior o desenvolvimento municipal (Firjan, 2020).

A dependência do FPM foi obtida a partir da representação dos recursos financeiros recebidos pelos municípios a título dessa transferência em relação ao montante total de receitas correntes. Essa relação mostra o quanto das receitas disponíveis são provenientes dos recursos transferidos pelo fundo do governo federal.

Para validação do método de RQ, o teste Wald foi aplicado para verificar a existência de diferenças significativas entre os diferentes quantis na relação entre a variável dependente e as variáveis explicativas. Utilizou-se também a reamostragem do bootstrap, possibilitando maior confiabilidade nas inferências realizadas, além de possibilitar a correção da heterocedasticidade, conforme sugere Cameron e Trivedi (2010).

\section{ANÁLISE DOS DADOS E DISCUSSÃO DOS RESULTADOS}

\subsection{Análise descritiva da amostra}

A fim de caracterizar a amostra estudada, procedeu-se à Análise Exploratória dos Dados (AED). Os resultados das estatísticas por grupo de municípios estão dispostos na Tabela 3. 
Tabela 3

Caracterização dos grupos de municípios

\begin{tabular}{|c|c|c|c|c|c|c|c|}
\hline \multirow[t]{3}{*}{ Grupo } & \multirow[t]{3}{*}{ Estat. } & \multicolumn{6}{|c|}{ Variáveis } \\
\hline & & \multicolumn{2}{|l|}{ Output } & \multicolumn{3}{|c|}{ Inputs } & \multirow[b]{2}{*}{ Tx_urb } \\
\hline & & Rec_trib_pc & VA_agro_pc & VA_ind_pc & VA_serv_pc & PIB_pc & \\
\hline G1 & Mínimo & 93,52 & 0,00 & 0,24 & 7,28 & 32254,86 & $39, \overline{31}$ \\
\hline \multirow[t]{4}{*}{ (68) } & Máximo & 1271,10 & 31,72 & 36,46 & 32,89 & 66981,00 & 100 \\
\hline & Média & 377,56 & 7,42 & 13,27 & 17,49 & 42297,93 & 72,13 \\
\hline & Desv. Padrão & 236,94 & 9,06 & 9,49 & 4,74 & 8007,85 & 15,23 \\
\hline & Coef. Var (\%) & 62,76 & 122,10 & 71,51 & 27,10 & 18,93 & 21,11 \\
\hline G2 & Mínimo & 40,59 & 0,01 & 0,48 & 6,53 & 16407,86 & 25 \\
\hline \multirow[t]{4}{*}{ (232) } & Máximo & 1001,56 & 16,55 & 13,65 & 21,83 & 31042,95 & 100 \\
\hline & Média & 217,79 & 3,90 & 3,64 & 12,19 & 21779,14 & 73,79 \\
\hline & Desv. Padrão & 127,28 & 3,47 & 2,91 & 2,69 & 4119,45 & 16,33 \\
\hline & Coef. Var (\%) & 58,44 & 88,97 & 79,94 & 22,07 & 18,91 & 22,13 \\
\hline G3 & Mínimo & 8,77 & 0,01 & 0,14 & 4,69 & 5446,60 & 20,19 \\
\hline \multirow[t]{4}{*}{$(516)$} & Máximo & 1065,67 & 7,42 & 7,48 & 12,96 & 16310,11 & 100 \\
\hline & Média & 100,24 & 1,77 & 0,85 & 7,75 & 10924,96 & 72,09 \\
\hline & Desv. Padrão & 87,39 & 1,31 & 0,80 & 1,42 & 2700,29 & 17,48 \\
\hline & Coef. Var (\%) & 87,18 & 74,01 & 94,11 & 18,32 & 24,72 & 24,25 \\
\hline
\end{tabular}

Testes estatísticos: $p$-value $<0,01$ para normalidade dos dados pelo teste de Shapiro-Wilk; $p$-value $<0,01$ para teste de homogeneidade de variância de Levene; $p$-value < 0,01 para diferenças entre os grupos 1, 2 e 3 pelo teste não paramétrico de Kruskal-Wallis, com exceção para a variável taxa de urbanização.

Notas: $* * *, * *$ e $*$ indicam, respectivamente, significância aos níveis de $1 \%, 5 \%$ e $10 \%$.

Fonte: Resultados da Pesquisa.

Pela técnica de cluster foram obtidos três agrupamentos de municípios, caracterizados quanto ao número de observações e comportamento das variáveis utilizadas para aglutinação. $\mathrm{O}$ maior grupo formado (G3) reúne mais de $63 \%$ do total da amostra e caracteriza-se pelo baixo valor das estatísticas calculadas. Neste grupo, a média da receita tributária própria é de R $\$ 100,24$ per capita, com um desvio padrão de $\mathrm{R} \$ 87,39$ e um mínimo de $\mathrm{R} \$ 8,77$, o que evidencia o pior desempenho tributário quando comparado aos demais grupos. A baixa arrecadação observada pode estar associada à baixa capacidade fiscal expressa pelas menores médias das variáveis de inputs. Este resultado corrobora os achados de Leroy et al. (2017), que identificaram que os municípios com baixo potencial arrecadatório possuíam baixos valores para população, renda, arrecadação própria, desenvolvimento socioeconômico e valor adicionado fiscal.

As maiores estatísticas foram observadas para o G1, formado por 68 municípios. A média do PIB per capita de $\mathrm{R} \$ 42.297,93$ e o desvio padrão associado $(\mathrm{R} \$ 8.007,85)$ revelam baixa dispersão entre os municípios deste grupo. Por outro lado, o valor adicionado fiscal da agropecuária mostrou grande variação $(122,10 \%)$. Isso porque, o grupo concentra municípios de todos os estratos populacionais, sendo que 55\% correspondem a municípios de pequeno porte, caracterizados pela produção econômica predominantemente agrícola. Também contempla o município com maior receita tributária per capita, aproximadamente $\mathrm{R} \$ 1$. 271,10, corroborando a afirmação de Baião et al. (2017), de que municípios com maior PIB per capita detêm maior capacidade de gerar receita tributária.

O segundo agrupamento, G2, é caracterizado por reunir 232 municípios com estatísticas medianas. Em relação aos demais grupos, apresentaram médias diferentes para todas as variáveis analisadas, exceto para a taxa de urbanização, que não se mostrou estatisticamente significativa para diferenciar os agrupamentos formados, conforme demonstrou o teste de Kruskal-Wallis. Ou seja, os agrupamentos de municípios demonstram médias iguais para a taxa de urbanização, contradizendo os argumentos da literatura, de que a maior urbanização estaria associada a maiores níveis de arrecadação tributária (Veloso, 2008). 
Embora o comportamento dos inputs seja uma referência para o desempenho tributário municipal, é necessário verificar o esforço arrecadatório empreendido pelos municípios na exploração de seu potencial tributário, isto é, o quão (in) eficientes eles têm sido na obtenção de receitas tributárias de sua competência.

\subsection{Análise da Eficiência Tributária dos municípios}

A aplicação da técnica DEA, abordagem BCC-output, permitiu identificar a eficiência tributária dos municípios mineiros no ano de 2016. A fim de realizar comparações quanto ao desempenho tributário municipal, a análise foi feita com base nos agrupamentos formados pela técnica de cluster e de acordo com o porte populacional dos municípios, conforme a Tabela 4.

Comparando os grupos, pode-se afirmar que aquele com melhores estatísticas para a eficiência tributária é o grupo 1 , com média geral de 0,5687 , desvio padrão de 0,3156 e coeficiente de variação de 55,49\%. Em geral, o grupo 1 contempla municípios enquadrados em todas as faixas populacionais, sendo proeminente a participação de municípios de pequeno porte. Dos 68 municípios que compõem esse agrupamento, $25 \%$ apresentaram escore de eficiência menor do que 0,3009 , metade apresentou escore menor do que 0,4459 e $25 \%$ maior do que 0,7872 , dentre esses últimos estão aqueles classificados como eficientes (IET=1,00).

Tabela 4

Estatísticas descritivas dos escores de eficiência por grupo e estrato populacional

\begin{tabular}{ccccccccccc}
\hline \multirow{2}{*}{ Grupo } & Estratos & & Média & Mínimo & Máximo & D. P & $\begin{array}{c}\text { C.V } \\
\text { (\%) }\end{array}$ & $\begin{array}{c}\mathbf{1}^{\mathbf{o}} \\
\text { Quartil }\end{array}$ & $\begin{array}{c}\text { Mediana } \\
\text { Quartil }\end{array}$ \\
\hline & Geral & $\mathbf{6 8}$ & $\mathbf{0 , 5 6 8 7}$ & $\mathbf{0 , 1 0 8 0}$ & $\mathbf{1 , 0 0}$ & $\mathbf{0 , 3 1 5 6}$ & $\mathbf{5 5 , 4 9}$ & $\mathbf{0 , 3 0 0 9}$ & $\mathbf{0 , 4 4 5 9}$ & $\mathbf{1 , 0 0}$ \\
& PP1 & 12 & 0,4416 & 0,1080 & 1,00 & 0,3364 & 76,18 & 0,1754 & 0,2712 & 0,7873 \\
& PP2 & 15 & 0,5864 & 0,1787 & 1,00 & 0,3254 & 55,49 & 0,3081 & 0,4356 & 1,00 \\
$\mathbf{1}$ & PP3 & 12 & 0,4805 & 0,1867 & 1,00 & 0,3114 & 64,81 & 0,2269 & 0,3162 & 0,7645 \\
& MP1 & 14 & 0,5776 & 0,2927 & 1,00 & 0,3003 & 51,99 & 0,3150 & 0,4535 & 1,00 \\
& MP2 & 6 & 0,6533 & 0,3484 & 1,00 & 0,2640 & 40,41 & 0,3662 & 0,6629 & 0,9050 \\
& GP1 & 7 & 0,6869 & 0,3633 & 1,00 & 0,3035 & 44,18 & 0,3791 & 0,6091 & 1,00 \\
& GP2 & 2 & 1,00 & 1,00 & 1,00 & 0,00 & 0 & 1,00 & 1,00 & 1,00 \\
\hline & Geral & $\mathbf{2 3 2}$ & $\mathbf{0 , 4 9 2 4}$ & $\mathbf{0 , 1 0 7 0}$ & $\mathbf{1 , 0 0}$ & $\mathbf{0 , 2 8 7 1}$ & $\mathbf{5 8 , 3 1}$ & $\mathbf{0 , 2 6 2 4}$ & $\mathbf{0 , 3 8 9 9}$ & $\mathbf{0 , 6 5 7 5}$ \\
& PP1 & 42 & 0,4498 & 0,1217 & 1,00 & 0,3029 & 67,34 & 0,2215 & 0,3431 & 0,6233 \\
& PP2 & 51 & 0,4534 & 0,1146 & 1,00 & 0,2911 & 64,20 & 0,2312 & 0,3222 & 0,5600 \\
& PP3 & 48 & 0,4728 & 0,1070 & 1,00 & 0,2984 & 63,11 & 0,2589 & 0,3628 & 0,6138 \\
& MP1 & 51 & 0,4769 & 0,2034 & 1,00 & 0,2686 & 56,32 & 0,2778 & 0,3667 & 0,6101 \\
& MP2 & 26 & 0,5864 & 0,2294 & 1,00 & 0,2495 & 42,55 & 0,3960 & 0,5841 & 0,7553 \\
& GP1 & 13 & 0,6887 & 0,3376 & 1,00 & 0,2248 & 32,64 & 0,5039 & 0,6315 & 0,9351 \\
& GP2 & 1 & 1,00 & 1,00 & 1,00 & NA & NA & 1,00 & 1,00 & 1,00 \\
\hline & Geral & $\mathbf{5 1 6}$ & $\mathbf{0 , 2 1 7 9}$ & $\mathbf{0 , 0 2 0 5}$ & $\mathbf{1 , 0 0}$ & $\mathbf{0 , 2 0 2 1}$ & $\mathbf{9 2 , 7 5}$ & $\mathbf{0 , 1 1 2 5}$ & $\mathbf{0 , 1 5 2 2}$ & $\mathbf{0 , 2 2 2 7}$ \\
& PP1 & 175 & 0,2117 & 0,0508 & 1,00 & 0,1962 & 92,67 & 0,1128 & 0,1511 & 0,2105 \\
& PP2 & 170 & 0,1970 & 0,0268 & 1,00 & 0,1615 & 81,98 & 0,1006 & 0,1425 & 0,2448 \\
& PP3 & 118 & 0,2260 & 0,0501 & 1,00 & 0,2220 & 98,23 & 0,1137 & 0,1526 & 0,2202 \\
& MP1 & 44 & 0,2279 & 0,0692 & 1,00 & 0,2032 & 89,16 & 0,1225 & 0,1751 & 0,2332 \\
& MP2 & 4 & 0,2476 & 0,0205 & 0,5596 & 0,2261 & 91,32 & 0,0614 & 0,2051 & 0,4762 \\
& GP1 & 5 & 0,8428 & 0,5683 & 1,00 & 0,2169 & 25,73 & 0,6072 & 1,00 & 1,00 \\
& GP2 & - & - & - & - & - & - & - & - & - \\
\hline
\end{tabular}

Teste Kruskal-Wallis: $p$-value $=0,000$

H0: não há diferenças nos escores de eficiência entre os três grupos de municípios

H1: há diferenças nos escores de eficiência entre os três grupos de municípios

Notas: PP1: Pequeno Porte 1; PP2: Pequeno Porte 2; PP3: Pequeno Porte 3; MP1: Médio Porte 1; MP2: Médio Porte 2; GP1: Grande Porte 1; GP2: Grande Porte 2 (conforme Tabela 1).

Fonte: Resultados da Pesquisa.

O grupo 2 apresentou média geral de 0,4924 e desvio padrão de 0,1070. Dentro desse grupo, existem $25 \%$ de municípios com escores menores que $0,2624,50 \%$ abaixo de 0,3899 e $25 \%$ acima 
de 0,6575 . Em todos os estratos populacionais desse agrupamento houve pelo menos um município que alcançou $100 \%$ de eficiência, como mostra a estatística máximo=1,00.

Já o agrupamento 3 mostrou-se contrário aos demais, visto que, além de apresentar o pior desempenho geral, com escore médio de 0,2179 , e maior variação entre os municípios agrupados, aproximadamente $92,75 \%$, também apresenta a maior amplitude em relação aos escores de eficiência. Comporta municípios que atingiram o mínimo de eficiência, 0,0205 e aqueles que foram eficientes na arrecadação tributária, máximo de 1,00.

De modo geral, há considerável dispersão entre os municípios quanto aos escores de eficiência, revelando elevada diferença entre os municípios em relação à exploração da base tributária, principalmente naqueles com população até 20 mil habitantes (PP1, PP2 e PP3). Essa dispersão sinaliza um potencial tributário existente em todas as classes populacionais. Gasparini e Miranda (2011) também identificaram grande variabilidade entre os municípios brasileiros no que tange à eficiência arrecadatória, revelando a presença de situações adequadas e insuficientes em todos os estados e regiões do país.

A fim de facilitar a identificação do total de municípios eficientes e ineficientes, é apresentada na Tabela 5 a frequência dos municípios dentro de cada grupo e para cada classe populacional.

Tabela 5

Frequência dos escores de (in) eficiência por classe populacional

\begin{tabular}{cccccccccc}
\hline Grupos & Situação & PP1 & PP2 & PP3 & MP1 & MP2 & GP1 & GP2 & Total \\
\hline \multirow{2}{*}{$\mathbf{1}$} & Ineficientes & 10 & 10 & 10 & 10 & 5 & 4 & - & 49 \\
& Eficientes & $\mathbf{2}$ & $\mathbf{5}$ & $\mathbf{2}$ & $\mathbf{4}$ & $\mathbf{1}$ & $\mathbf{3}$ & $\mathbf{2}$ & $\mathbf{1 9}$ \\
\hline \multirow{2}{*}{$\mathbf{2}$} & Ineficientes & 34 & 42 & 38 & 44 & 22 & 10 & - & 190 \\
& Eficientes & $\mathbf{8}$ & $\mathbf{9}$ & $\mathbf{1 0}$ & $\mathbf{7}$ & $\mathbf{4}$ & $\mathbf{3}$ & $\mathbf{1}$ & $\mathbf{4 2}$ \\
\hline \multirow{2}{*}{$\mathbf{3}$} & Ineficientes & 170 & 167 & 112 & 43 & 4 & 2 & - & 498 \\
& Eficientes & $\mathbf{5}$ & $\mathbf{3}$ & $\mathbf{6}$ & $\mathbf{1}$ & - & $\mathbf{3}$ & - & $\mathbf{1 8}$ \\
\hline & Total & 229 & 236 & 178 & 109 & 36 & 25 & 3 & 816 \\
\hline
\end{tabular}

Fonte: Resultados da pesquisa.

Pela Tabela 5 é possível perceber que apenas 79 municípios foram eficientes na exploração de sua base tributária, dentre os quais, 19 são pertencentes ao grupo 1, 42 ao grupo 2 e 18 ao grupo 3 .

Quando a análise recai para as classes populacionais, nota-se que todos os municípios enquadrados no estrato grande porte 2 foram eficientes, sendo eles: Belo Horizonte (G1), Contagem (G1) e Juiz de Fora (G2). Quanto aos estratos de médio porte, cuja população varia de 20 a 100 mil habitantes, o número de municípios ineficientes foi expressivo, $94,12 \%$ do total enquadrado nessa categoria. Esse resultado contraria os achados de Veloso (2008), para os quais municípios médios, com população entre 20 e 100 mil habitantes, apresentaram o maior esforço tributário. Logo, tais resultados permitem inferir que os municípios podem ser eficientes na arrecadação tributária, independente do seu porte populacional.

A dispersão dos escores de eficiência entre os grupos, de forma geral, e entre os estratos populacionais, em particular, evidencia um potencial tributário não explorado, visto que em algumas situações, municípios de pequeno porte foram mais eficientes que os de médio porte (grupo 3). Essa variabilidade em termos de desempenho tributário também foi constatada por Souza et al. (2007), Massardi e Abrantes (2015) e Fernandes e Sousa (2018), sugerindo que a eficiência tributária é afetada por fatores alheios à capacidade fiscal dos entes.

A distribuição espacial dos municípios em relação à (in) eficiência tributária pode ser visualizada pela Figura 1, que desmembra os níveis de ineficiência apresentados pelos municípios mineiros.

Visualiza-se no mapa que todas as mesorregiões mineiras são representadas por municípios que demonstraram 100\% no desempenho tributário. Ao estabelecer um ranking das mesorregiões 
com maior número de municípios eficientes, tem-se: i) Metropolitana de Belo Horizonte (22); ii) Sul/Sudoeste de Minas (13); iii) Vale do Rio Doce e Zona da Mata (8 cada); iv) Triângulo Mineiro/Alto Paranaíba (7); iv) Norte de Minas (5); v) Noroeste de Minas e Oeste de Minas (4 cada); vi) Campo das Vertentes e Vale do Mucuri (3 cada); e vii) Central Mineira e Jequitinhonha (1 cada).

Figura 1

Distribuição espacial dos municípios mineiros em relação à (in) eficiência tributária

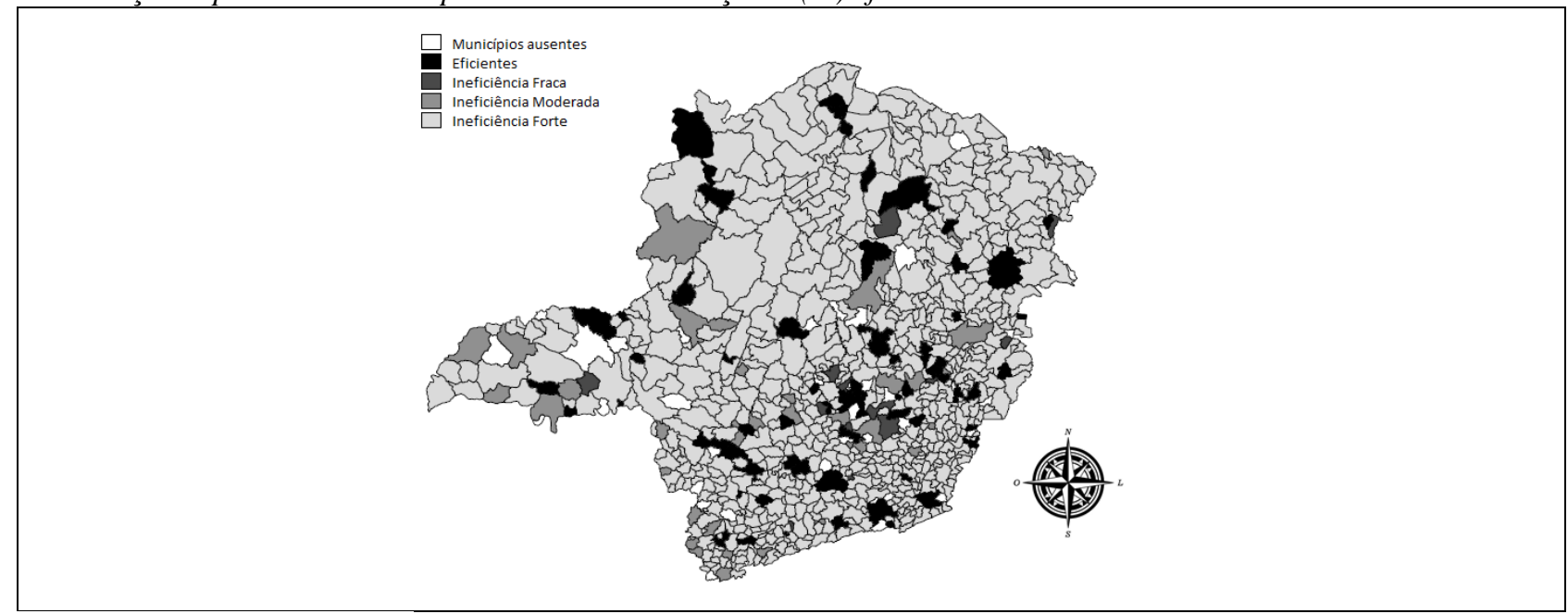

Fonte: Resultados da pesquisa.

Tabela 6

Análise da perda tributária dos municípios ineficientes (em R\$)

\begin{tabular}{|c|c|c|c|c|c|c|c|}
\hline Grupo & Estrato & $\begin{array}{c}\text { Indice } \\
\text { de } \\
\text { Eficiência }^{1}\end{array}$ & $\begin{array}{c}\text { Receita } \\
\text { Tributária } \\
\text { Efetiva (1) }\end{array}$ & $\begin{array}{c}\text { Receita } \\
\text { Tributária } \\
\text { Potencial }(2)^{2}\end{array}$ & $\begin{array}{c}\begin{array}{c}\text { Perda } \\
\text { Tributária }\end{array} \\
(2-1)\end{array}$ & $\begin{array}{c}\text { Esforço } \\
\text { Fiscal } \\
(1 / 2)\end{array}$ & FPM \\
\hline \multirow{6}{*}{1} & PP1 & 3,384 & $949.748,01$ & $3.214 .517,12$ & $2.264 .769,11$ & 0,2955 & $8.662 .544,03$ \\
\hline & PP2 & 2,498 & $2.270 .269,79$ & $5.672 .042,04$ & $3.401 .772,25$ & 0,4003 & $8.838 .850,24$ \\
\hline & PP3 & 2,687 & $4.195 .398,00$ & $11.275 .132,13$ & 7.079.734,13 & 0,3721 & $13.172 .734,37$ \\
\hline & MP1 & 2,409 & $13.411 .079,38$ & $32.307 .290,23$ & $18.896 .210,85$ & 0,4151 & $23.435 .074,29$ \\
\hline & MP2 & 1,919 & $38.566 .412,40$ & $74.008 .945,40$ & $35.442 .533,00$ & 0,5211 & $38.556 .941,09$ \\
\hline & GP1 & 2,331 & $130.506 .592,51$ & $304.210 .866,00$ & $173.704 .273,50$ & 0,4290 & $78.551 .838,01$ \\
\hline \multirow{6}{*}{2} & PP1 & 3,466 & $523.189,98$ & $1.813 .376,47$ & $1.290 .186,49$ & 0,2885 & $8.522 .810,41$ \\
\hline & PP2 & 3,234 & $1.318 .408,59$ & $4.263 .997,06$ & $2.945 .588,41$ & 0,3092 & $8.739 .832,72$ \\
\hline & PP3 & 3,103 & $2.893 .236,00$ & $8.979 .157,93$ & $6.085 .921,93$ & 0,3222 & $14.300 .546,50$ \\
\hline & MP1 & 2,626 & $7.494 .536,17$ & 19.687.397,06 & $12.192 .860,89$ & 0,3807 & 21.403 .765 .97 \\
\hline & MP2 & 2,053 & $24.506 .032,92$ & $50.332 .941,01$ & $25.826 .908,09$ & 0,4869 & $36.949 .123,06$ \\
\hline & GP1 & 1,762 & $69.035 .512,60$ & $121.702 .705,20$ & $52.667 .192,60$ & 0,5672 & $62.724 .824,55$ \\
\hline \multirow{6}{*}{3} & PP1 & 6,122 & $360.596,07$ & $2.207 .893,67$ & $1.847 .297,60$ & 0,1633 & $8.515 .559,50$ \\
\hline & PP2 & 6,452 & $593.993,76$ & $3.832 .566,54$ & $3.238 .572,78$ & 0,1550 & $8.656 .328,50$ \\
\hline & PP3 & 6,302 & $1.294 .103,13$ & $8.155 .696,75$ & $6.861 .593,62$ & 0,1587 & $13.353 .219,07$ \\
\hline & MP1 & 5,381 & $3.392 .772,94$ & $18.258 .546,75$ & $14.865 .773,81$ & 0,1858 & $21.211 .444,33$ \\
\hline & MP2 & 4,185 & $7.736 .695,03$ & $32.381 .163,38$ & $24.644 .468,35$ & 0,2389 & $26.460 .450,26$ \\
\hline & GP1 & 1,632 & $27.943 .007,68$ & $45.611 .371,44$ & $17.668 .363,76$ & 0,6126 & $47.641 .842,18$ \\
\hline \multicolumn{2}{|c|}{ Total } & 3,419 & $18.721 .754,72$ & 41.550.867,01 & $22.829 .112,29$ & 0,3501 & $25.193 .762,54$ \\
\hline
\end{tabular}

Notas: ${ }^{1}$ Média ponderada pelas receitas efetivas; ${ }^{2}$ Receita Tributária Potencial= índice de eficiência $*$ Receita Tributária Efetiva.

Fonte: Resultados da Pesquisa.

A distribuição espacial dos municípios ineficientes é bem dispersa, abrangendo todo o território do estado. Os municípios que apresentaram ineficiência fraca foram aqueles que se mostraram próximos à fronteira de eficiência, com escores entre 0,80 e 1,00, isto é, revelaram até 
$20 \%$ de ineficiência na arrecadação de tributos. De forma análoga, os municípios com ineficiência moderada tiveram escore entre 0,60 e 0,80 e os de forte ineficiência até 0,60 , sendo estes predominantes em todo o território estadual, indicados pela cor mais clara no mapa. $\mathrm{O}$ grande número de municípios com ineficiência até $40 \%$ (forte ineficiência), 688 no total, imprime um quadro preocupante quanto à autonomia financeira municipal, visto que, nesses municípios, aparentemente, a complementação das receitas públicas seria necessária.

A fim de identificar a importância do FPM em função da capacidade fiscal dos municípios, estimaram-se, por meio dos escores de eficiência, as médias da receita tributária potencial dos municípios considerados ineficientes e a perda tributária para cada classe populacional (Tabela 6).

Pela Tabela 6 nota-se que as médias dos escores de eficiência obtidos pela DEA estão acima de 1, visto que foram calculadas pelo critério de Farrel. Indicam o quanto as receitas tributárias poderiam ser aumentadas, dado o seu nível de insumos (base tributária) (Pereira, 2015). Nessa metodologia, quanto mais próximo de 1 , mais próximo da eficiência a unidade governamental está. De modo geral, observa-se que, em média, os municípios mineiros poderiam ampliar em mais de três vezes suas receitas, visto que o aproveitamento da capacidade tributária foi de aproximadamente $35,01 \%$. Detalhadamente, observa-se que os municípios de pequeno porte 1 (G1) poderiam aumentar, em média, 3,38 vezes as suas receitas, o que implicaria em menor perda tributária. Na situação atual, tais municípios deixaram de arrecadar, em média, $\mathrm{R} \$ 2.264 .769,11$, aproximadamente 70,45\% do potencial tributário existente. Em quase todos os estratos populacionais o montante de recursos que não foram arrecadados superou as receitas efetivamente arrecadadas, indicando que esses municípios poderiam aumentar seus níveis de receitas próprias, melhorando o desempenho da gestão tributária. Souza et al. (2007) e Gasparini e Miranda (2011) também identificaram perda tributária entre municípios de diferentes portes populacionais.

O maior esforço de arrecadação foi observado para os municípios de grande porte 1 (G3), visto que tiveram um aproveitamento de $61,26 \%$ do seu potencial tributário. Nota-se, portanto, um amplo espaço para aumentar o esforço tributário dos municípios mineiros, assim como apontado por Sousa et al. (2012) para os municípios brasileiros.

Para algumas municipalidades, a importância do FPM na composição da receita e, por conseguinte, a dependência financeira, seria reduzida consideravelmente se as bases tributárias fossem exploradas eficientemente. Fundamentalmente, para os municípios de pequeno porte do grupo 3, cujas médias das variáveis representativas da base tributária foram as menores da amostra, conforme discutido anteriormente (Tabela 3), a transferência do FPM seria reduzida, em média, $21,7 \%, 37,4 \%$ e 51,4\% para os municípios enquadrados no PP1, PP2 e PP3, respectivamente. Esse resultado é corroborado por Gasparini e Miranda (2011), que ao avaliarem o nível de transferências ótimas em função da eficiência tributária dos municípios, identificaram que não haveria necessidade de se complementar, por meio do FPM, as receitas já disponíveis nos municípios. Ambos achados reforçam a necessidade e importância de estimular a gestão tributária municipal.

É possível também comparar a perda tributária dos municípios ineficientes com o montante médio de recursos recebidos via transferência do FPM. Ao que tudo indica, parece existir uma associação entre ineficiência tributária e transferências intergovernamentais, visto que dentre os municípios ineficientes, os que apresentaram o maior volume de receitas negligenciadas (R\$ 173.704.273,50) foram também os que exibiram maior média da receita do FPM (R \$ 78.551.838,01). Trata-se dos municípios de grande porte 2, pertencentes ao grupo 1. Para estes municípios, há a possibilidade de reduzir a dependência do FPM por meio da exploração eficiente do potencial fiscal existente em sua base tributária, visto que a perda tributária foi duas vezes maior que a transferência federal recebida. Conforme aponta a literatura (Cossio, 1998; Veloso, 2008; Orair \& Alencar, 2010; Sobrinho \& Alencar, 2019), as transferências intergovernamentais geram um desincentivo à arrecadação de tributos, implicando em baixos níveis de eficiência tributária. Para os municípios do estado da Paraíba, Fernandes e Sousa (2018) comprovaram que a eficiência tributária era afetada negativamente pela dependência do FPM. 


\subsection{Relação da (In) eficiência Tributária com Desenvolvimento Socioeconômico e Dependência do FPM}

Para verificar se a (in) eficiência tributária varia em função do desenvolvimento socioeconômico e da dependência do FPM, foram estimadas 5 regressões para os quantis 10\%, 25\%, $50 \%, 75 \%$ e $90 \%$ da distribuição da variável dependente. Espera-se verificar o grau de associação da IFDM e da dependência do FPM com a eficiência tributária nos diferentes quantis pré-determinados. Na Tabela 7 estão os coeficientes calculados e as expectativas teóricas, bem como os testes estatísticos associados.

Conforme resultado do teste de Wald, pode-se afirmar, ao nível de $1 \%$ de significância, que apenas os coeficientes estimados da variável dependência do FPM foram diferentes em todos os quantis de distribuição da variável dependência. Logo, o efeito da dependência do FPM varia ao longo dos quantis do Índice de Eficiência Tributária dos municípios.

Os resultados obtidos pela Regressão Quantílica confirmam as expectativas teóricas das variáveis admitidas no estudo. O efeito da dependência do FPM no nível de (in) eficiência tributária dos municípios é negativo, atestando o desincentivo provocado pelas transferências intergovernamentais no desempenho fiscal dos governos receptores, assim como nas pesquisas de Souza et al. (2007), Massardi e Abrantes (2015), Siqueira et al. (2016) e Fernandes e Sousa (2018). Da mesma forma que nesses estudos, verificou-se que à medida que a participação do FPM aumenta na estrutura de financiamento do setor público, menor tende a ser o engajamento do governo local em explorar suas bases tributárias.

Tabela 7

Resultados da Regressão Quantílica

\begin{tabular}{|c|c|c|c|c|c|c|c|}
\hline \multirow[t]{2}{*}{ Variáveis } & \multirow[t]{2}{*}{ Expectativa Teórica } & \multicolumn{6}{|c|}{ Coeficientes } \\
\hline & & q.10 & $q .25$ & $\mathbf{q . 5 0}$ & $q .75$ & $\mathbf{q . 9 0}$ & MQO \\
\hline \multirow{3}{*}{ Dep_FPM } & & $-0,3780$ & $-0,4838$ & $-0,6650$ & $-1,0150$ & $-1,2453$ & $-0,8358$ \\
\hline & $(-)$ & $(0,0479)$ & $(0,0378)$ & $(0,0709)$ & $(0,1096)$ & $(0,2235)$ & $(0,0732)$ \\
\hline & & $0,000 * * *$ & $0,000 * * *$ & $0,000 * * *$ & $0,000 * * *$ & $0,000 * * *$ & $0,000 * * *$ \\
\hline \multirow{3}{*}{ IFDM } & & 0,3260 & 0,2831 & 0,3701 & 0,3934 & 0,2635 & 0,3541 \\
\hline & $(+)$ & $(0,0698)$ & $(0,0740)$ & $(0,1253)$ & $(0,2686)$ & $(0,6617)$ & $(0,1465)$ \\
\hline & & $0,000 * * *$ & $0,000 * * *$ & $0,003 * * *$ & 0,143 & 0,691 & $0,0159 * *$ \\
\hline \multirow{3}{*}{ Constante } & & 0,0594 & 0,1856 & 0,2821 & 0,5678 & 1,0563 & 0,4538 \\
\hline & & $(0,0562)$ & $(0,0592)$ & $(0,1038)$ & $(0,2060)$ & $(0,5173)$ & $(0,1179)$ \\
\hline & & 0,295 & $0,002 * * *$ & $0,007 * * *$ & $0,006 * * *$ & $0,041 * *$ & \\
\hline Pseudo $\mathbf{R}^{2}$ & & 0,0605 & 0,0941 & 0,1273 & 0,1486 & 0,1076 & \\
\hline \multirow[t]{2}{*}{ Teste de Wald } & Dep_FPM & \multirow{2}{*}{\multicolumn{4}{|c|}{$\begin{array}{l}\text { Prob }>F=0.0000 \\
\text { Prob }>F=0.8872\end{array}$}} & & \\
\hline & IFDM & & & & & & \\
\hline
\end{tabular}

Nota: ***, ** e * indicam, respectivamente, significância aos níveis de 1\%, 5\% e 10\%. Os valores entre parênteses são as estimações dos erros padrões robustos.

Fonte: Resultados da pesquisa.

O IFDM exerce um efeito positivo e significativo para os quantis 10, 25 e 50, sugerindo que para os municípios mais ineficientes (ineficiência forte), aumentar o nível de desenvolvimento socioeconômico contribui para maximizar a arrecadação tributária, sustentando os achados de Massardi e Abrantes (2015) e Leroy et al. (2017). Os resultados encontrados corroboram a tese de que as disparidades no grau de desenvolvimento socioeconômico condicionam a distribuição horizontal da arrecadação tributária, como apontado por Cossio (1998).

\section{CONSIDERAÇÕES FINAIS}

A análise realizada mostra que existe um potencial tributário pouco explorado entre os municípios de Minas Gerais, isto é, os municípios estão arrecadando abaixo da sua capacidade 
tributária. Apenas 79 municípios apresentaram 100\% de aproveitamento de sua base tributária, dentre os quais, 19 são pertencentes ao grupo 1, 42 ao grupo 2 e 18 ao grupo 3.

Quanto à localização geográfica, observou-se que a região Metropolitana de Belo Horizonte comporta o maior número de municípios eficientes, 22 no total. Por outro lado, foi possível notar que todas as mesorregiões tiveram municípios com baixo desempenho tributário. Essa constatação indica que parece não haver um padrão de comportamento entre municípios eficientes e ineficientes, no que tange à localização geográfica e tamanho populacional, visto que tanto municípios de pequeno porte quanto de grande porte, enquadrados nos três agrupamentos analisados, mostraram-se ineficientes.

Para os municípios ineficientes, observou-se que apenas 35,01\% da capacidade tributária estava sendo devidamente explorada. Esses resultados geram implicações para a análise do volume de recursos tributários arrecadados, sugerindo que a baixa arrecadação pode estar mais relacionada à falta de vontade política ou baixo esforço fiscal, do que propriamente à limitação das bases tributárias municipais. No entanto, a comprovação empírica do efeito desses fatores políticos no desempenho tributário requer um referencial teórico que suporte essa relação e variáveis que expliquem se o ônus político da tributação compensa ou não o esforço de arrecadação, sendo essa uma pauta para agenda de pesquisas futuras.

No que se refere ao IFDM, comprovou-se o que aponta a literatura, de que localidades mais desenvolvidas tendem a ter bases tributárias maiores e maior capacidade de obtenção de recursos tributários. Esses resultados legitimam a importância de sistemas de redistribuição de renda frente as disparidades no grau de desenvolvimento, as quais determinam uma distribuição desigual de capacidade tributária, que por sua vez, explicam as diferenças no grau de esforço fiscal das administrações tributárias municipais.

O efeito negativo do FPM nos escores de (in) eficiência tributária confirma a existência de um comportamento 'preguiçoso' na obtenção de recursos próprios por parte de um elevado número de municípios, resultando em alta dependência financeira e subutilização das bases tributárias próprias. Dentre os municípios ineficientes, identificou-se uma maior possibilidade de expansão da arrecadação própria para os de pequeno porte, pertencentes ao grupo 3, visto que apresentaram apenas 16,33\% (PP1), 15,50\% (PP2) e 15,87\% (PP3) de seu potencial tributário efetivamente utilizado. Dessa forma, a perda tributária decorrente do potencial tributário não explorado acaba sendo compensada pelos recursos transferidos via FPM.

A partir dos resultados encontrados, pode-se depreender que a dependência financeira dos municípios pode ser reduzida na medida em que o esforço na obtenção de recursos tributários próprios seja ampliado. Essa informação é relevante na medida em que permite identificar as situações nas quais o compartilhamento de recursos é mais necessário para fins de equalização fiscal, tomando como base a capacidade tributária dos municípios e sua eficiência na arrecadação própria.

Os achados deste estudou contribuem com a administração pública brasileira, especificamente no que se refere à estruturação do sistema tributário nacional. Sinalizam a necessidade de aperfeiçoamento dos critérios de redistribuição dos recursos do FPM, mais condizentes com a realidade experimentada pelos municípios, de modo a possibilitar uma distribuição mais justa e equitativa. Todavia, por analisar apenas a capacidade fiscal dos municípios, sem levar em consideração a sua necessidade fiscal, este estudo se limita ao efeito do FPM na eficiência tributária, não sendo possível discutir sobre o real impacto desses recursos na equalização fiscal dos municípios. O presente estudo abre um precedente para que indicadores de eficiência tributária sejam utilizados como elementos condicionantes de um sistema de equalização de recursos públicos. Nessa perspectiva, pesquisas envolvendo essas questões também são desejáveis.

\section{REFERÊNCIAS}

Baião, A. L., Cunha, A. S. M. D., \& Souza, F. S. R. N. D. (2017). Papel das transferências intergovernamentais na equalização fiscal dos municípios brasileiros. Revista do Serviço Público, 68(3), 583-610. 
Banker, R. D., Charnes, A., \& Cooper, W. W. (1984). Some models for estimating technical and scale inefficiencies in data envelopment analysis. Management Science, 30(9), 1078-1092.

Brito, J. R. S., Brito, J. V. C. S. (2020). Estrutura fiscal dos municípios potiguares: Autonomia ou dependência? Revista Interface, 17(2), 106-128.

Cameron, A. C., \& Trivedi, P. K. (2010). Microeconometrics using stata (Vol. 2). College Station, TX: Stata press.

Campelo, C. A. G. B. (2003). Eficiência municipal: um estudo no estado de São Paulo. [Tese de doutorado, Universidade de São Paulo], São Paulo, Brasil.

Charnes, A., Cooper, W. W., \& Rhodes, E. (1978). Measuring the efficiency of decision making units. European Journal of Operational Research, 2(6), 429-444.

Constituição da República Federativa do Brasil. (1988). Brasília. http://www.planalto.gov.br/ccivil_03/constituicao/constituicao.htm

Cossio, F. A. B. (1998). Disparidades econômicas inter-regionais, capacidade de obtenção de recursos tributários, esforço fiscal e gasto público no federalismo brasileiro. [Dissertação de mestrado, Pontifícia Universidade Católica do Rio de Janeiro], Rio de Janeiro, Brasil.

Costa, C. C. D. M., Ferreira, M. A. M., Braga, M. J., \& Abrantes, L. A. (2015). Fatores associados à eficiência na alocação de recursos públicos à luz do modelo de regressão quantílica. Revista de Administração Pública, 49(5), 1319-1347.

De Mello Jr, L. R. (2000). Fiscal decentralization and intergovernmental fiscal relations: a cross-country analysis. World Development, 28(2), 365-380.

Diniz, J. A., \& Corrar, L. J. (2011). Análise da relação entre a eficiência e as fontes de recursos dos gastos municipais no ensino fundamental. Sociedade, Contabilidade e Gestão, 6(1), 135-149.

Fernandes, L. H. D. S., \& Sousa, M. C. S. (2018). Eficiência tributária municipal e seus determinantes: Uma abordagem semi-paramétrica via regressão beta. Pesquisa Operacional para o Desenvolvimento, 10(3), 160-178.

Fundação Getúlio Vargas. FGV. Carga tributária no Brasil: 1990-2018. Observatório de Política Fiscal. https://observatorio-politica-fiscal.ibre.fgv.br/posts/carga-tributaria-no-brasil-1990-2018

Gasparini, C. E., \& Miranda, R. B. (2011). Transferências, equidade e eficiência municipal no Brasil. Planejamento e Políticas Públicas, 36(1), 311-349.

Golany, B., \& Roll, Y. (1989). An application procedure for DEA. Omega, 17(3), 237-250. Índice Firjan de Desenvolvimento Municipal. Rio de Janeiro. http://www.firjan.org.br/ifdm/.

Leroy, R. S. D., Abrantes, L. A., Almeida, F. M., Ferreira, M. A. M., \& Vieira, M. A. (2017). Estrutura arrecadatória e desenvolvimento socioeconômico dos municípios mineiros. Desenvolvimento em Questão, 15(41), 164-201.

Lopes, R. P. M., \& Vieira, O. H. P. (2019). Esforço Fiscal e ônus político: uma análise do desempenho dos municípios baianos na arrecadação do IPTU. Anais do VI Encontro Nacional de Administração Pública, Salvador, BA, Brasil.

Louzano, J. P. O., Abrantes, A. L., Ferreira, M. A. M., \& Zuccolotto, R. (2019). Causalidade de Granger do índice de desenvolvimento socioeconômico na gestão fiscal dos municípios brasileiros. Revista de Administração Pública, 53(3), 610-627.

Massardi, W. O., \& Abrantes, L. A. (2015). Esforço fiscal, dependência do FPM e desenvolvimento socioeconômico: Um estudo aplicado aos municípios de Minas Gerais. REGE Revista de Gestão, 22(3), 295-313.

Mattos, E., Rocha, F., \& Arvate, P. (2011). Flypaper effect revisited: evidence for tax collection efficiency in Brazilian municipalities. Estudos Econômicos, 41(2), 239-267.

Mendes, M., Miranda, R. B., \& Cossio, F. (2008). Transferências intergovernamentais no Brasil: diagnóstico e proposta de reforma. Senado Federal, Consultoria Legislativa, Brasília, Brasil.

Mendes, W. A., Ferreira, M. A. M., Abrantes, A. L., \& Faria, E. R (2018). A influência da capacidade econômica e da formação de receitas públicas no desenvolvimento humano. Revista de Administração Pública, 52(5), 918-934.

Moraes, D. P. (2006). Arrecadação tributária municipal: Esforço fiscal, transferências e Lei de Responsabilidade Fiscal. [Dissertação de mestrado, Fundação Getúlio Vargas], São Paulo, Brasil.

Musgrave, R. A., \& Musgrave, P. B. (1980). Finanças públicas: teoria e prática. São Paulo: Campus.

Oates, W. E. (1999). An essay on fiscal federalism. Journal of Economic Literature, 37(3), 1120-1149. 
Orair, R. O., \& Albuquerque, P. H. M. (2016). Capacidade de arrecadação do IPTU: Um exercício de estimação por fronteira estocástica com dado em painel dos municípios brasileiros no período de 2002-2014. Anais do Encontro Nacional de Economia, Foz do Iguaçu, PR, Brasil.

Orair, R. O., \& Alencar, A. A. (2010). Esforço fiscal dos municípios: Indicadores de condicionalidade para o sistema de transferências intergovernamentais. Monografia premiada do Tesouro Nacional, Brasília.

Pereira, L. F. V. N. (2015). R: Um software livre para mensuração da eficiência. In: Boueri, R., Rocha, F., \& Rodopoulos, F. (Eds.). Avaliação da qualidade do gasto público e mensuração da eficiência (pp. 333375). Secretaria do Tesouro Nacional.

Prud'Homme, R. (1995). The dangers of decentralization. The World Bank Research Observer, 10(2), 201220.

Shah, A. (1991). The new fiscal federalism in Brazil (No. 124). Washington, DC: World Bank.

Shah, A. (2007). The practice of fiscal federalism: Comparative perspectives (Vol. 4). McGill-Queen's PressMQUP.

Siqueira, K. J. S. P., Lima, R. C. A., \& Paes, N. L. (2016). Eficiência na administração tributária dos municípios: O caso da arrecadação em Pernambuco. Revista Brasileira de Economia de Empresas, 16(2), 97-120.

Sobrinho, A. L., \& de Alencar, F. A. G. (2019). Análise do esforço fiscal na arrecadação do IPTU para os municípios do estado do Ceará utilizando modelo de fronteira estocástica. Revista Controle-Doutrina e Artigos, 17(1), 170-200.

Sousa, M. D. C. S. D., Araújo, P. L. D. C. P., \& Tannuri-Pianto, M. E. (2012). Residual and technical tax efficiency scores for Brazilian municipalities: A two-stage approach. Estudos Econômicos (São Paulo), 42(1), 43-74.

Souza, C. O., Silva, O. M., Ferreira, M. A. M., \& Abrantes, A. L. (2007). Esforço de arrecadação tributária nos municípios da Zona da Mata Mineira. Anais do XXXI Encontro Nacional da ANPAD, Rio de Janeiro, Brasil.

Tiebout, C. M. (1956) A pure theory of local expenditures. Journal of Political Economy, 64(5), $416-424$.

Tristão, J. A. M. (2002). A administração tributária dos municípios brasileiros: Aplicação da análise de clusters para elaboração de uma tipologia do comportamento tributário municipal. Revista de Economia $e$ Administração, 1(3), 79-93.

Veloso, J. F. A. (2008). As transferências intergovernamentais e o esforço tributário municipal: uma análise do fundo de participação dos municípios (FPM). [Dissertação de mestrado, Universidade de Brasília], Brasília, Brasil. 